\title{
EFFECTS OF NONSPECIFIC SMOOTH MUSCLE RELAXANTS AND Ca-BLOCKER ON Ca-RELEASE AND Ca-BINDING IN MICROSOMAL FRACTIONS FROM RABBIT TAENIA COLI
}

\author{
Issei TAKAYANAGI, Tetsuhiro HISAYAMA and Sae SUZUKI \\ Department of Chemical Pharmacology, Toho University School of \\ Pharmaceutical Sciences, Miyama, Funabashi, Chiba 274, Japan
}

Accepted April 28, 1980

\begin{abstract}
Effects of nonspecific smooth muscle relaxants, papaverine $\left(10^{-4} \mathrm{M}\right)$ and Aspaminol (1,1-diphenyl-3-piperidinobutanol hydrochloride, $\left.10^{-4} \mathrm{M}\right)$, and Ca-blocker, D-600 $\left(10^{-6} \mathrm{M}\right)$ on Ca-release and Ca-binding in the microsomal fractions of rabbit taenia coli were determined. The doses necessary to relax the K-depolarized taenia coli maximally were used. Ca-binding in the microsomal fractions was inhibited by Aspaminol and D-600 and increased by papaverine in the concentration used. On the other hand, Ca-release from the Ca-incorporated microsomal fractions was inhibited by papaverine and Aspaminol but was not influenced by D-600. Changes observed in Ca-transfer may be related to relaxation of smooth muscle induced by the test drugs.
\end{abstract}

It was reported that nonspecific smooth muscle relaxants, papaverine and Aspaminol, and $\mathrm{Ca}$-blockers inhibited the responses of $\mathrm{K}$-depolarized intestinal smooth muscle to $\mathrm{CaCl}_{2}$ and also decreased Ca-uptake by the depolarized intestinal smooth muscle from the bath fluid (1). Since papaverine is a potent inhibitor of cyclic AMP-phosphodiesterase (2), relaxation of smooth muscle is considered to be partly due to an increase of intracellular levels of cyclic AMP. However, Aspaminol and Ca-blockers are found to have little inhibitory action on phosphodiesterase activity $(3,4)$. Nonspecific inhibitory action of Aspaminol $(5,6)$ and of Ca-blockers (7) can be decreased to a great extent by increasing the $\mathrm{Ca}$-concentration in the bath fluid, while that of papaverine is only slightly increased. As little is known of the differences in the effects of the smooth muscle relaxants and Ca-blockers on Ca-release and Ca-binding in the microsomal fractions from the intestinal smooth muscle and of differences in changes in Ca-transfer induced by the nonspecific smooth muscle relaxants and Ca-blockers, we carried out studies in an attempt at elucidation.

\section{MATERIALS AND METHODS}

A piece ( 3 to $4 \mathrm{~cm}$ ) of the taenia coli isolated from male rabbits, weighing 2 to $3 \mathrm{~kg}$, was suspended in a $20 \mathrm{ml}$ organ bath filled with a $\mathrm{KCl}$-solution kept at $32^{\circ} \mathrm{C}$ and gassed with a mixture of $95 \% \mathrm{O}_{2}$ and $5 \% \mathrm{CO}_{2}$. Responses to drugs were recorded isotonically. The KCl-solution used had the following composition (mM): $\mathrm{KCl} 159.6, \mathrm{CaCl}_{2} 2.2, \mathrm{MgCl}_{2}$ 2.1, $\mathrm{NaHCO}_{3} 5.9$ and glucose 2.8.

Estimation of Ca-binding in the microsomal fractions was carried out by the method of Carsten (8) and as modified by Takayanagi et al. (9). The taenia coli was immediately 
removed from 3 male rabbits and washed with ice-cold $0.25 \mathrm{M}$ sucrose solution. The isolated tissue was minced and homogenized in 9 volumes of ice-cold $0.25 \mathrm{M}$ sucrose containing $0.01 \mathrm{M}$ Tris-HCl buffer $\left(\mathrm{pH} 7.4\right.$ at $4^{\circ} \mathrm{C}$ ) in a Polytron (P.T.-10, Brinkman Instruments) with the rheostat setting 8 for 5 seconds. The homogenate was centrifuged at $9,000 \times \mathrm{g}$ for $20 \mathrm{~min}$. The supernatant was again centrifuged at $15,000 \times \mathrm{g}$ for $20 \mathrm{~min}$. Centrifugation of the supernatant at $40,000 \times \mathrm{g}$ for 90 min resulted in a pellet which was used as the microsomal fractions in this study. Ca-binding was studied at $32^{\circ} \mathrm{C}$ in the incubation mixture which contained $100 \mathrm{mM} \mathrm{KCl}, 5 \mathrm{mM} \mathrm{MgCl}_{2}, 5 \mathrm{mM}$ potassium oxalate, $5 \mathrm{mM}$ sodium azide, $20 \mu \mathrm{M} \mathrm{CaCl}_{2}$ plus ${ }^{45} \mathrm{Ca}(0.02 \mu \mathrm{Ci} / \mathrm{ml}), 3 \mathrm{mM}$ ATP and $30 \mathrm{mM}$ histidine buffer ( $\mathrm{pH} 7.4$ at $4{ }^{\circ} \mathrm{C}$ ) in a total volume of $5 \mathrm{ml}$. The assay was initiated by the addition of the microsomal fractions to the incubation mixture. The radioactive $\mathrm{Ca}$ retained was estimated by liquid scintillation spectrometry, after the filters had been dissolved in $1 \mathrm{ml}$ of methylcellusolve for 12 $\mathrm{hr}$ and then $10 \mathrm{ml}$ of a toluene-methanol $(700: 300 \mathrm{v} / \mathrm{v})$ containing $4 \mathrm{~g}$ of 2,5-diphenyloxazole and $0.1 \mathrm{~g}$ of 1,4-bis [2-(4-methyl-5-phenyloxazoly)] benzene (dimethyl POPOP) in a litre. Cabinding was estimated from the radioactivity of the filter. The values were corrected for the ${ }^{45} \mathrm{Ca}$ remaining on the filters in the absence of the microsomal fractions. Protein was assayed by the method of Lowry et al. (10), using bovine serum albumin as the standard. The amount of protein contained in the incubation mixture was about $100 \mu \mathrm{g} / \mathrm{ml}$.

Ca-release was determined as follows. The microsomal fractions were incubated in the medium similar to that used for Ca-uptake experiments except that the concentration of microsomal proteins was increased two-fold. The microsomal proteins were allowed to accumulate $\mathrm{Ca}$ for $10 \mathrm{~min}$. The release of incorporated $\mathrm{Ca}$ was started at $32^{\circ} \mathrm{C}$ by ten-fold dilution of the medium with the release medium which was made by omitting $\mathrm{CaCl}_{2}$ and potassium oxalate from the incubation medium. Samples of $1 \mathrm{ml}$ were removed from the release medium at a timed interval and passed through a Millipore filter. ${ }^{45} \mathrm{Ca}$ associated with the microsomal fractions was determined as reported previously (9). Drugs used: Papaverine hydrochloride (Wako-Junyaku), Aspaminol (1,1-diphenyl-3piperidinobutanol hydrochloride: Kowa), D-600 (Knoll) and ${ }^{45} \mathrm{CaCl}_{2}$ (specific activity: $16.5 \mathrm{mCi} / \mathrm{mg} \mathrm{Ca}$; New England Nuclear Corp.). All chemicals used were of analytical grade. Drug-concentrations indicate the salt form.

\section{RESULTS}

When the rabbit taenia coli was immersed in normal physiological solution, spontaneous tonus did not develop, therefore, the isotonic $\mathrm{KCl}$-solution was used as the bath fluid. Dose-relaxation curves of papaverine, Aspaminol and D-600 in the $\mathrm{KCl}$-depolarized taenia coli are shown in Fig. 1. In the following experiments, $10^{-6} \mathrm{M}$ was used for D-600 as the dose necessary to induce the maximum relaxation of taenia coli, and $10^{-4} \mathrm{M}$ for Aspaminol and papaverine.

Preliminary tests indicated that the variance between Ca-binding capacities of the microsomal fractions obtained from different groups of rabbits was larger than that within Ca-binding capacities of the microsomal fractions from the same group of rabbits. Therefore, 
the results in a series of experiments of Ca-binding and Ca-release were obtained at the same time of year, using one group of rabbits.

Ca-binding decreased by omitting ATP from the medium. Aspaminol $\left(10^{-4} \mathrm{M}\right)$ and D-600 $\left(10^{-4} \mathrm{M}\right)$ were inhibited significantly $(\mathrm{P}<0.05)$ at all the incubation times tested, as shown in Table 1. Papaverine $\left(10^{-4} \mathrm{M}\right)$ increased significantly $(\mathrm{P}<0.05)$ Ca-binding (Table 1), as reported previously (6).

Since the rate of Ca-release from the microsomal fractions was rapid in the absence of

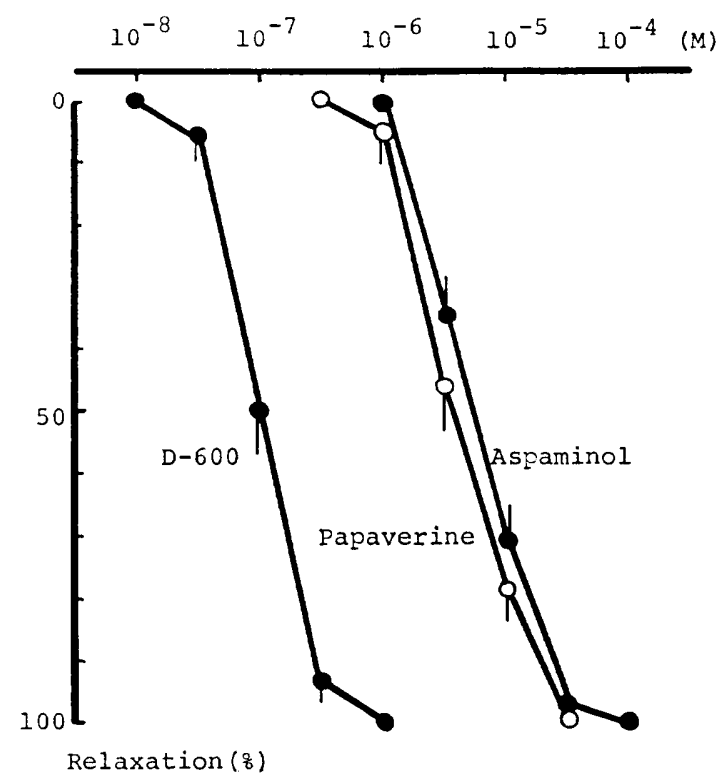

FIG. 1. Dose-relaxation curves of papaverine, Aspaminol and D-600. Values are presented as the means with S.E. of 8 experiments.

TABLE 1. Effects of papaverine, Aspaminol and D-600 on Ca-binding in the microsomal fractions of rabbit taenia coli.

\begin{tabular}{lrcc}
\hline & \multicolumn{3}{c}{ Incubation time } \\
\cline { 2 - 4 } & $2 \mathrm{~min}$ & $5 \mathrm{~min}$ & $10 \mathrm{~min}$ \\
\hline ATP $(-)$ & $1.3 \pm 0.2$ & $4.1 \pm 1.0$ & $6.3 \pm 0.5$ \\
ATP $(3 \mathrm{mM})($ Control $)$ & $10.3 \pm 0.6$ & $21.3 \pm 0.8$ & $25.6 \pm 1.1$ \\
ATP $(3 \mathrm{mM})+$ Papaverine $\left(10^{-4} \mathrm{M}\right)$ & $11.4 \pm 0.7$ & $25.3 \pm 0.7^{*}$ & $29.8 \pm 0.9^{*}$ \\
ATP $(3 \mathrm{mM})($ Control $)$ & $9.6 \pm 0.5$ & $22.4 \pm 1.3$ & $26.8 \pm 1.2$ \\
ATP $(3 \mathrm{mM})+$ Aspaminol $\left(10^{-4} \mathrm{M}\right)$ & $6.1 \pm 0.3^{*}$ & $15.5 \pm 0.9^{*}$ & $19.2 \pm 1.1^{*}$ \\
ATP $(3 \mathrm{mM})($ Control $)$ & & $29.5 \pm 0.6$ & $41.8 \pm 1.0$ \\
ATP $(3 \mathrm{mM})+\mathrm{D}-600\left(10^{-6} \mathrm{M}\right)$ & & $25.0 \pm 0.4^{*}$ & $37.2 \pm 0.9^{*}$ \\
\hline
\end{tabular}

Values of Ca-binding are expressed in nmoles $\mathrm{Ca} / \mathrm{mg}$ protein and presented as the means \pm S.E. of 5 experiments.

*: significant difference from the corresponding control values at $\mathrm{P}<0.05$. $\operatorname{ATP}(-)$ :

in the absence of ATP $(3 \mathrm{mM})$ 


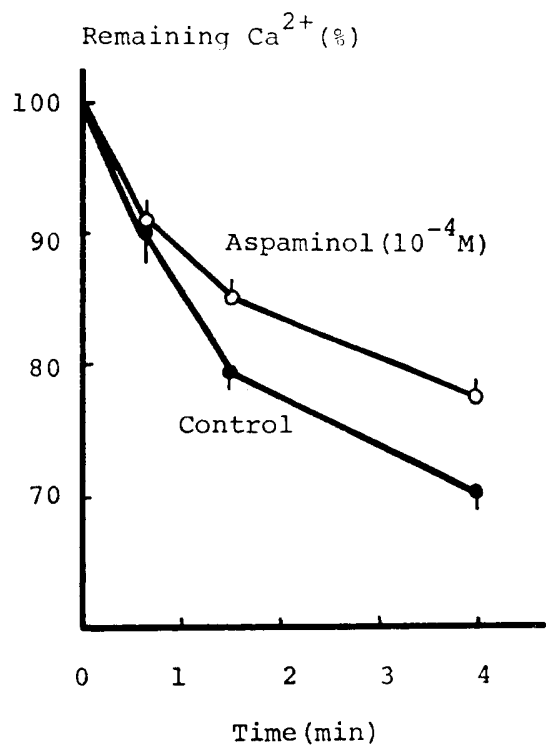

Fig. 2. Effect of papaverine $\left(10^{-4} \mathrm{M}\right)$ on $\mathrm{Ca}$ release from the Ca-incorporated microsomal fractions of rabbit taenia coli. The amount of $\mathrm{Ca}^{2+}$ in microsomal fractions at 0 time was considered as $100 \%$. Values are presented as the means and S.E. of 5 experiments. The values in the presence of papaverine are significantly $(P<0.05)$ different from the control values at the incubation times of 1.5 and $4 \mathrm{~min}$.

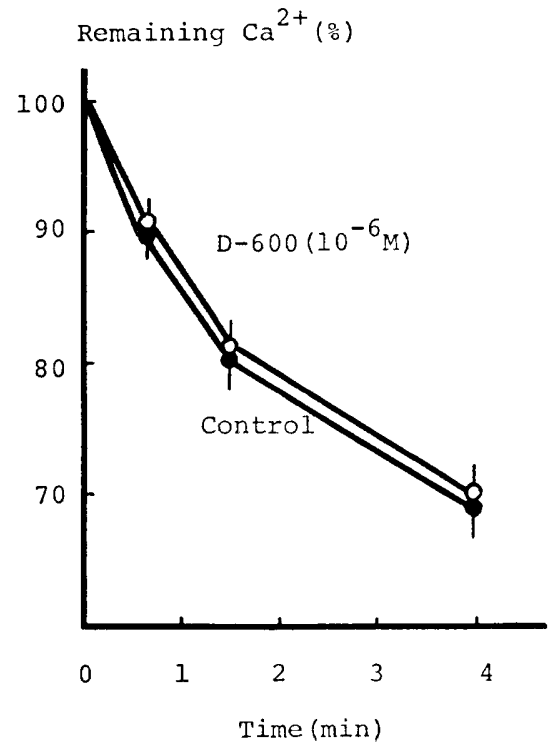

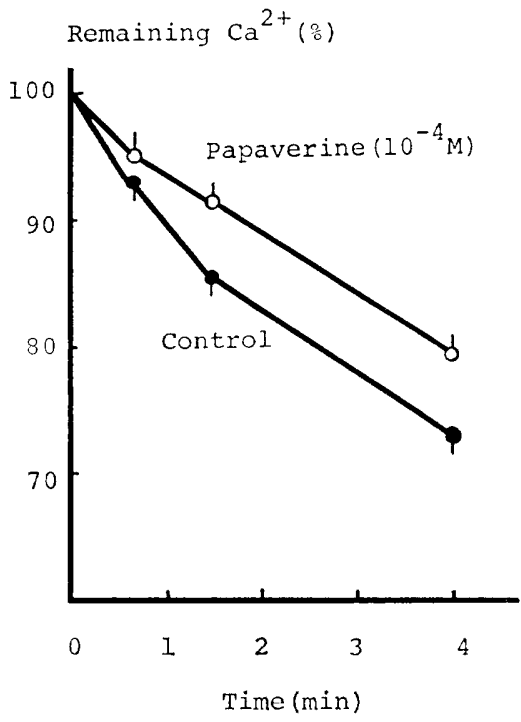

FIG. 3. Effects of Aspaminol $\left(10^{-4} \mathrm{M}\right)$ on Carelease from the Ca-incorporated microsomal fractions of rabbit taenia coli. The amount of $\mathrm{Ca}^{2+}$ in microsomal fractions at 0 time was considered as $100 \%$. Values are presented as the means with S.E. of 5 experiments. The values in the presence of Aspaminol are significantly $(\mathrm{P}<0.05)$ different from the control values at the incubation times of 1.5 and $4 \mathrm{~min}$.

Fig. 4. Ca-release from the Ca-incorporated microsomal fractions of rabbit taenia coli in the presence or absence of D-600 $\left(10^{-6} \mathrm{M}\right)$. The amount of $\mathrm{Ca}^{2+}$ in microsomal fractions at 0 time was considered as $100 \%$. Values are presented as the means \pm S.E. of 5 experiments. The values in the presence of D-600 are not significantly $(P>0.05)$ different from the control values. 
ATP, effects of the drugs were tested in the presence of ATP $(3 \mathrm{mM})$. The rate of Carelease was significantly $(\mathrm{P}<0.05)$ inhibited at the incubation times of 1.5 and $4 \mathrm{~min}$ by $10^{-4} \mathrm{M}$ of papaverine (Fig. 2) and Aspaminol (Fig. 3), while Ca-blocker, D-600 (10-6 M) had little influence on the Ca-release (Fig. 4).

The microsomal fractions used in this paper contained high concentrations of marker enzymes of plasma membrane, such as true cholinesterase, $5^{\prime}$-nucleotidase and $\mathrm{Na}$ - and $\mathrm{K}$ ATPase. Ca- and Mg-ATPase which is concerned with the sarcoplasmic reticulum was also found in the fractions. Electron microscopic observation indicated that there were no intact mitochondria in the fractions. Precise data are not shown in this paper, as the findings were much the same as previously reported by Takayanagi et al. (9).

\section{DISCUSSION}

Microsomal binding of $\mathrm{Ca}^{2+}$ may have a physiological significance, if it contributes to regulation of the concentrations of cytoplasmic $\mathrm{Ca}^{2+}$ and contraction-relaxation states of muscle fibres. The finding that Aspaminol and D-600 inhibited Ca-binding in the microsomal fractions suggests that these compounds decrease the concentrations of cytoplasmic $\mathrm{Ca}^{2+}$ and relax the muscle fibres by inhibiting the Ca-influx, if they complete with $\mathrm{Ca}^{2+}$ at binding sites concerned with Ca-influx process, as discussed previously (6).

The mechanisms involved in smooth muscle relaxation by papaverine seem to be complex with regard to Ca-transfer. In the present work, papaverine potentiated Ca-binding in the microsomal fractions. Andersson and Nilsson (11), using the microsomal fraction from rabbit colon, found that the Ca-accumulating capacity of the microsomal fractions was potentiated by cyclic AMP. Similar findings were also reported in the microsomal fractions from rabbit aorta (12) and from rat uterus (13). Therefore, potentiation of the Ca-binding in the microsomal fractions, as induced by papaverine may be due to elevation in the levels of cyclic AMP with the inhibition of phosphodiesterase. On the other hand, papaverine was found to have inhibitory actions on Ca-uptake in depolarized intestinal smooth muscle (1) and did not potentiate Ca-binding in the microsomal fractions in the higher concentration $\left(3 \times 10^{-4} \mathrm{M}\right)(14)$. This drug did, however, potentiate Ca-binding in lower concentrations. Thus, papaverine has inhibitory actions on Ca-binding in microsomal fractions, in addition to the stimulatory action which may be mediated through cyclic AMP. Nonspecific inhibitory action of Aspaminol (6) and Ca-blockers $(4,7)$ was decreased to a great extent by increasing the Ca-concentration in the bath. These results suggest that inhibition of Cabinding induced by Aspaminol and D-600 was due to a competition of Aspaminol and D-600 with $\mathrm{Ca}^{2+}$ at the binding sites in the microsomal fractions.

The opposite effects of drugs, which increased Ca-binding and decreased Ca-release, are compatible with the physiological significance of the observed Ca-transfer, given the relaxing properties of the drugs. In this study Ca-release from the microsomal fractions which had incorporated $\mathrm{Ca}$ was inhibited by papaverine and Aspaminol but not by D-600. These findings suggest that the inhibition of Ca-release was concerned with relaxation of the intestinal smooth muscle by papaverine and Aspaminol and clarified that there was a 
difference in changes in Ca-transfer induced by Aspaminol and D-600. The inhibition of Ca-release by papaverine may be, at least partly, due to accumulation of cyclic AMP in the cells. Mechanisms related to the inhibition of Ca-release induced by Aspaminol were not clarified.

Enzymatic activities and electron microscopic observations suggested that the microsomal fractions used in our study consisted of plasma membrane and sarcoplasmic reticulum. Therefore, Ca-binding and Ca-release observed in the crude microsomal fractions represent only a net effect. Further studies of the effects of drugs on purified membrane fractions should provide a more extensive elucidation.

\section{REFERENCES}

1) Takayanagi, I., Karasawa, A. and Kasuya, Y.: Relaxation of depolarized guinea pig taenia caecum induced by some antispasmodics, Europ. J. Pharmacol. 50, 137-143 (1978)

2) PöCh, G., Juan, H. And KukovetZ, W.K.: Papaverine-induced inhibition of phosphodiesterase activity in various mammalian tissues, Life Sci. 10, 133-144 (1971)

3) Takayanagi, I., Uchida, U., Abe, T., Tomiyama, A. And Takagi, K.: Relaxing action of synthetic antispasmodics on the intestinal smooth muscle, Japan. J. Pharmacol. 23, 737-739 (1973)

4) Pöch, G. ANd Umfahrer, W.: Differentiation of intestinal smooth muscle relaxation caused by drugs that inhibit phosphodiesterase, Naunyn-Schmied. Arch. Pharmacol. 239, 257-268 (1976)

5) Takagi, K. and Takayanagi, I.: Drug-receptors, Physiology and Pharmacology in Smooth Muscles, Edited by Bando, T., TAKaGl, K. AND Ebashi, S., p. 187-219, Nankodo, Tokyo (1974) (in Japanese)

6) Takayanagi, I., Yamashita, H., Manda, T. and Takagi, K.: Ca ions and relaxation of intestinal smooth muscle induced by papaverine and Aspaminol, Japan. J. Pharmacol. 27, 311-314 (1977)

7) Fleckenstein, A., Grün, G., Trithart, H. and Byon, K.: Uterus-relaxation druch hochaktive Ca-antagonistische Hemmstoffe der elektro-mechanischen Koppelung wie Isoptin (Verapamil, Iproveratrill), Substanz D-600 und Segontin (Prenylamiun), Klin. Wschr. 49, 32-41 (1971)

8) CARSTEN, M.E.: Role of calcium binding by sarcoplasmic reticulum in the contraction and relaxation of uterine smooth muscle, J. gen. Physiol. 53, 414-426 (1969)

9) Takayanagi, I., Hongo, H., Hisayama, T. and Kasuya, Y.: Effects of acetylcholine and histamine on mechanical activity of rabbit taenia coli, Ca-incorporation and $\mathrm{Ca}$ release in its microsomal fraction, J. Pharm. Dyn. 2, 212-218 (1979)

10) Lowry, O.H., Rosebrough, N.J., Farr, A.L. And Randall, R.J.: Protein measurement with the Folin phenol reagent, J. biol. Chem. 193, 265-275 (1951)

11) Andersson, R. and Nilsson, K.: Cyclic AMP and calcium in relaxation in intestinal smooth muscle, Nature, New Biol. 238, 119-120 (1972)

12) Baudouin-Legros, M. And Meyer, P.: Effects of angiotensin, catecholamines and cyclic AMP on calcium storage in aortic microsomes, Brit. J. Pharmacol. 47, 377-385 (1973)

13) Nishikori, K., Takanaka, T. and Maeno, A.: Stimulation of microsomal calcium uptake and protein phosphorylation by adenosine cyclic $3^{\prime}, 5^{\prime}$-monophosphate in rat uterus, Mol. Pharmacol. 13, 671-678 (1977)

14) Takayanagi, I., Hisayama, T., Yoshida, Y. and Koike, K.: Effects of nonspecific smooth muscle relaxants on calcium-uptake by microsomal fraction and their inhibitory action in rabbit taenia coli, J. Pharm. Dyn. 3, 160-166 (1980) 